\title{
Swamping and Spoon-feeding: literacies for learning in further education
}

\author{
RICHARD EDWARDS \& JUNE SMITH \\ University of Stirling, United Kingdom
}

\begin{abstract}
This article reports on the outcomes of the first phase of the Literacies for Learning in Further Education project, which is exploring the literacy practices required for successful study within different curriculum areas in four Further Education Colleges, two in Scotland and two in England. It draws upon initial interview data with staff and students to explore the perceptions of literacy as an issue for learning within further education. This suggests a complex picture of assumptions and expectations on the part of staff and students, which are not always aligned and impact upon the teaching and learning situation. In particular, issues are raised of 'swamping' students with texts, which there is little expectation of them reading and of 'spoon-feeding' students, because of a perception of their limitations in literacy.
\end{abstract}

\section{Introduction}

Recent work on literacy (Barton \& Hamilton, 1998; Barton et al, 2000) has noted that there are strong links between the activities of reading and writing, and the social settings in which people live, work and study. This suggests that the ways in which people use and understand reading and writing in their daily lives are dependent on different local cultures and contexts. The focus here is not on basic skills as a set of individual skills and competences alone, but on literacy as situated in particular social contexts. Some of the starting points for this area of research are:

- people often make sense of life through a variety of ways of writing and reading;

- we are literate in different ways in different settings;

- some ways of reading and writing are deemed more worthwhile, valuable and influential than others;

- literacy practices change over time, as with those now associated with information and communications technologies; 
- literacy practices are often learned outside formal education institutions.

Students engage in diverse literacy practices as the means for learning across the full range of the curriculum. As such, these practices are crucial resources for enhancing learning outcomes, access and inclusion, potentially mediating participation in a range of contexts. As students participate in courses in different areas of the curriculum, we would expect their literacies would be different in different subject areas.

The Literacies for Learning in Further Education (LfLFE, available at www.lancs.ac.uk/lflfe/) research project has been funded for 3 years from January 2004 as part of Phase 3 of the United Kingdom's Teaching and Learning Research Programme (TLRP). A key aim of the TLRP is to improve the outcomes - however specified - for learners in teaching and learning contexts. The LfLFE project involves collaboration between two universities - University of Stirling and Lancaster University - and four further education colleges in Scotland and England - Anniesland College in Glasgow, Lancaster and Morecambe College, Perth College and Preston College. A central concern for the project is to understand how the literacy practices required of college life and being a student relate to the wide range of students' literacy practices - the knowledge and capabilities they involve and the texts and modalities they address, which support learning across the curriculum. The research focuses on the use, refinement and diversification of literacy events and practices in further education.

The premise for the project is that the literacy practices of colleges are not always fashioned around the resources people bring to student life and that students may have more resources to draw upon than people working in colleges might be aware. Over the 3 years of the project, we are exploring ways of mobilising students' everyday literacy practices in different ways to enhance their learning in 13 curriculum areas in further education. The intention is to achieve a critical understanding of the movement and flows of literacy practices in people's lives: how literacy practices are ordered and re-ordered, networked or overlapped across domains (home-college, virtual-real, reading-writing), across social roles in students' lives and what objects might mediate such mobilisations. The LfLFE project explores the literacy practices that each participant has accumulated during their life-course to date, the literacy practices required by their course of study and, crucially, the potentials of the ongoing developmental interaction between these literacies. In other words, we explore the beneficial interaction between students' informal vernacular literacy practices and the formal literacies required by their college learning.

The project is in three Phases. Phase 1, between January and July 2004, was an Induction period, in which we were involved in the 
recruitment of university- and college-based researchers to the project. We also used this Phase to explore the literacy practices required by students in becoming a student in further education. Phase 2, which will run until July 2005, is examining in detail the literacy practices of students in 13 curriculum areas across the domains of college, work, home and community. The final Phase of the project will involve developing and evaluating pedagogic interventions based upon our initial data collection and analysis, to try and establish whether there are ways of mobilising learners' resources to support learning, retention and achievement.

This article reports on the outcomes of Phase 1 of the project and is in three parts. In the first, we will sketch the conceptual framings that are informing our research. These include work in New Literacy Studies and multimodal social semiotics (Barton, et al, 2000). The second part of the article will outline the methodology adopted for Phase 1 of the project. Given the length restraints of an article, we will focus more on methods than broader methodological considerations. In the third part we will outline the key outcomes of analysis of Phase 1 data. The analysis is illuminative of issues being carried forward within the project, but we feel it offers insights, which may be of interest to the wider field. We will only focus on the key outcomes primarily, but not solely derived from the Scottish end of the project, once again for length reasons, but also because the analysis is not something that simply comes to an end, but is recursive as we progress the project over time. We therefore expect some aspects of the analysis to be taken further and others less so. The concluding part of the article will outline the ways in which Phase 1 analysis is influencing Phase 2 data collection.

\section{Multimodal Literacy Practices}

Traditionally, literacy has been taken to mean reading and writing formal paper-based texts using predetermined rules surrounding the use of a national language. This view sees literacy as an autonomous value-free attribute laying within the individual - a set of singular and transferable technical skills that can be taught, measured and tested at a level of competence. A range of initiatives are aimed at enhancing the attainment of literacy as part of the agenda for the improvement of 'basic skills', 'key skills', 'core skills', 'core competencies' or 'learning to learn'. These include the government's response to the Tomlinson Review in England and Higher Still in Scotland, and the competence-based frameworks for National Vocational Qualifications (NVQs) and Scottish Vocational Qualifications (SVQs). Embedded in such initiatives is a focus on communication skills, computer literacy and literacy-dependent transferable skills. These initiatives focus on the induction of people of all ages into at least 'functional' literacy and numeracy. 
The LfLFE project seeks to complement and inform practice and policies in relation to these initiatives. However, we do not treat literacy simply as a set of autonomous skills and competencies. To do so, leads to a view of literacy as a cognitive property of each individual mind, to an idea that literacy can be taught, learned and demonstrated entirely independent of a context of use, and to attempts to measure how much literacy each individual has.

Our approach draws upon the New Literacy Studies, which offers a socially situated and constructed view of literacies as multiple, emergent and situated in particular contexts (Barton et al, 2000). This is what is referred to as a social practices approach to literacy. This approach encourages us to talk differently about how documents get read and written as embedded in the everyday activities of life. It also leads us, like others (Tuomi-Grohn \& Engestrom, 2003; Eraut, 2004), to question a simple view that 'skills' can be 'transferred' unproblematically from context to context. To cross borders between contexts entails a disembedding and recontextualisation of practices, including literacy, which are not fully captured in autonomous models of literacy.

The key concepts in a social practices view of literacy are 'literacy event' and 'literacy practice'. The use of the term 'literacy event' has evolved from Heath (1986) to describe observable actions or groups of actions in which text plays a role. The use of 'practices' extends this idea to include descriptions of values, understandings and intentions. As such, literacy practices are not static and one literacy event can be invested with multiple values and intentions. This leads us to focus on differences in literacy practices from one context to another, and on the values, knowledge, and expectations that are ascribed to them and that shape the identities of those who participate in them. Here, context can be read at a variety of levels, such as life, college, subject, course and teaching session.

The LfLFE project builds on a pilot study, which found that further education students engaged in a sophisticated and complex variety of literacy practices outside the college that were not mobilised into collegerelated literacy events (Smith, 2004). It was this study that has led us to conceive our task as to support the border crossing of literacy practices from the vernacular and informal to the formal. These include literacy practices associated with the screen, as well as those of the page, and the hybrid forms of multimodality, e.g. text, icons, pictures, through which people read and write these days. This enables these literacy practices to become resources for learning in the teaching and assessment associated with attainment in particular subject areas.

This perspective on literacies potentially has profound effects on how we name the pedagogical imperatives relating to literacy in all educational sectors and, in particular, the place of further education in addressing the United Kingdom's government's lifelong learning agenda. 
It also indicates that relating the literacies required by study in further education to those from other contexts is an activity in its own right and not simply a transfer of technical skills from one context to another.

\section{Methodology and Methods}

The methodology informing this project is broadly ethnographic, hermeneutic and reflexive. It is ethnographic as we seek to describe through fieldwork, in as much detail as possible, the literacy practices required by the study of particular subjects in becoming a further education student and those that learners manifest in the diverse contexts of their lives. This dimension is largely descriptive as we attempt to understand the culture and rituals of further education, and the artefacts and totems through which literacy is mobilised. We are trying to obtain 'thick description' from the inside, rather than merely act as observers from the outside. For this reason, we are partnering further education staff and students as members of the research team, rather than them being simply respondents. Here, our aim is to support participants in becoming ethnographers of their own experience. The project is hermeneutic insofar as we recognise the recursive role of interpretation in the understanding of social practices; that is, the ways in which understanding is mobilised through the interrelationships between persons and artefacts, and that these understandings help to shape future practices. We are therefore looking to understand, as well as describe literacy practices, but from within, rather than above.

This has resulted in a mixed method approach to the project as a whole and to Phase 1 in particular. Phase 1 involved the appointment of a university-based researcher to each university and a college-based researcher, seconded for 1.5-2 days per week, for each college. They have been involved in observation, semi-structured interviews and the collection of documents. Observations in Phase 1 were generated by simply being in the colleges and examining the artefacts available, e.g. signs on notice boards, leaflets in guidance centres, and their use by staff and students. These were recorded in research diaries and helped to inform interview schedules. Interviews were held with a randomly chosen sample of staff and, to a lesser extent, students. The number of interviews and categories can be found in Table I.

These interviews lasted about an hour and were transcribed. In addition, there was a questionnaire distributed to college staff, which sought information on the artefacts and text types used in further education, and the purposes for their use. Both questionnaire and interview schedule were piloted and modified on a number of occasions in the light of the experience of use and feedback. 


\begin{tabular}{|c|c|c|c|c|}
\hline & & $\begin{array}{c}\text { Subject } \\
\text { teaching } \\
\text { staff }\end{array}$ & $\begin{array}{c}\text { Suppor } \\
\text { t staff }\end{array}$ & Students \\
\hline Anniesland & & 6 & 6 & 10 \\
\hline Lancaster & and & 5 & 4 & 7 \\
\hline \multicolumn{5}{|l|}{ Morecambe } \\
\hline Perth & & 6 & 5 & 5 \\
\hline Preston & & 5 & 5 & 19 \\
\hline Total & & 22 & 20 & 41 \\
\hline
\end{tabular}

Table I. Phase 1 interviews.

For this article, we have drawn from the analysis of interviews, which were recorded and transcribed, and questionnaires, and sought confirmation of emerging issues or challenges to them from observations. The interviews were analysed from two perspectives, theory- and datadriven. The theory-driven coding framework was derived from the questionnaire, which itself had been modified from an existing Australian questionnaire instrument to take account of a different context and more recent research. Each interview was coded using this framework. In a distributed research project, such as this one, with many people involved in the coding, questions of reliability arise. In order to address this, samples of transcripts were independently coded by each member of the research team, who had been subdivided into college-focused groups. These groups met to discuss their coding and to address any differences. To a large extent there was a high consistency of coding across the research team and differences were reconciled through discussion. In this way, we sought to build inter-researcher reliability. The data driven coding looked for emerging themes within the interview data and a similar process of discussion was used to generate inter-researcher reliability.

The returns of the questionnaire proved somewhat disappointing. This appears to have been due in part to the paper overload being experienced by further education staff, which results in the prioritising of that which is immediately most important, that is, their teaching. It may also have been in part due to the unfamiliarity of some of the concepts within the questionnaire and their openness to interpretation. Although piloted and amended, in retrospect, we feel such instruments have limited value for research of this sort. The poor response rate meant that we did not attempt to analyse the data statistically, as it would not have been significant. Instead, we have drawn upon it to triangulate our interview data.

Coding is only part of analysis, as the latter still entails a sensemaking process. We do not claim the outcomes of our Phase 1 analysis as findings in any complete sense. We present them here as the sense we 
have made to date of the data as supportable by the evidence we have and the methodology of the project. The analysis is illuminative of a number of themes and issues in researching this topic in the context of further education.

This brings up to the reflexive aspect of the methodology, as the above suggests, a relatively smooth implementation of a research design, a genre of writing more associated with experimental designs (and the natural sciences per se) than with social science in the context of naturalistic environments. Reflexivity entails us surfacing our own assumptions and rationales, and pointing to the work we are doing through the genre of discourse through which we are communicating. For the purposes of this article, therefore, we have smoothed over the 'strategic improvisations' (Polkinghorne, 1997) that have been part of our Phase 1 activities. A large distributed research project in naturalistic environments is not the same as conducting the same experiment in a distributed number of laboratories; nor would we expect it to be. However, it is the latter that often semiotically codes readers' understanding of 'research'. So it is important that this project is not read in this way. Articles of limited length can only be summaries of some part of a large research project and we will discuss our improvisations elsewhere.

Similarly, we would not like the analysis we offer to be read as exhaustive and definitive. The latter is often coded in terms of 'findings' and with qualitative data the notion of saturation is often used to suggest that as much as is possible has been extracted from the data collected. Our view is somewhat different, as while being rigorous, we do not believe data can be either saturated or exhausted (unlike the researcher perhaps!). Data is always open to reinterpretation in the light of changing circumstances and different theoretical perspectives. Thus, our analysis is more of a finding, but within a certain context of work. That finding is one based upon multiple data sources and the process of inter-researcher reliability. However, any finding also involves a covering up, as in bringing to the fore key themes, others are placed to one side. Once again, this is both for practical reasons - articles can only be of a certain length, but also reflexively, we would argue that this is inherent in the sense-making process. We follow Stronach \& MacLure (1997) that every opening relies upon a closing and vice versa. In opening up our finding, we are closing others that we might have travelled, thereby producing a particular map of a landscape. We would claim this to be a methodological strength of this project.

\section{Finding Literacy Practices}

Phase 1 of the LfLFE project has produced emerging insights into the interrelated processes of becoming a student in further education and 
becoming a student of a certain subject in further education. There is thus a dual process at play in becoming a student, embracing both institution and subject.

Thus, for instance, on entering college, students receive a large amount of induction materials designed to help them understand processes and procedures, and identify sources of help. Induction is at three levels: the college, the faculty or department and the subject. Some of this material can therefore tend to be repetitious. However, our interviews with both staff and students indicate that neither anticipated that these would be read. The purpose of the texts produced and their introduction to students early on in their college lives would therefore appear to have a certain symbolic value, rather than substantially helping students in navigating their way into student life. This situation is also potentially exacerbated by the provision of subject induction materials in addition to college-wide materials. There is thus a swamping of students with written information at an early stage in their college lives.

There is the anticipation of students not reading texts produced for them and often the assumption that students are not able to navigate large amounts of text. This raises questions of why such texts are produced. Some staff identified strategies to help interpret texts for students. However, the students interviewed suggested that their lack of interaction with materials produced for them is because they are unclear of their use and relevance, and because they are not engaged by the tone, language and visual design of that with which they are presented. While we are cautious about the extent to which this is the case for all students, there would appear to be an interesting issue that written information does not necessarily inform students in the ways in which staff would like.

In relation to becoming a student of a particular subject, lecturing staff interviewed tended to assume that students do not read, in particular extended texts. To help students, staff in some areas indicated they simplify teaching and assessment artefacts, which they identify themselves as unsatisfactory 'spoon-feeding'. For instance, a Computing lecturer commented about handouts to students:

ah think I really did just redo it and make it just easier for them to read and not so much ... not so challenging ah don't think.

This simplification often ends towards a reductionism, presenting students with a bulleted text, which decontextualises the material presented. A problem arises when this decontextualisation takes place to such an extent that the content of the artefact loses substantive meaning.

Thus, students tend not to be introduced to extended texts in their subject settings. Inevitably, there are exceptions to this, such as the use of complete plays in Drama. However, the overall tendency emerging from the data suggests limited engagement with extended texts in most 
subject areas. When discussing this with students, we found that a significant proportion talked of the teaching artefacts as 'unchallenging'. This suggests that at least some of the strategies adopted by staff to assist students with their learning, based on their perceptions of the inadequacy of student literacy practices, is not effective for a lot of those students. Phase 1 student interviews indicated that students mostly engage in a wide range of screen- and page-based literacy practices in their everyday lives, in particular in relation to reading. This has been confirmed in our Phase 2 data collection, which suggests a lecturer expectancy effect in terms of the texts produced to support student learning, which may 'over-crutch' the students, thereby limiting possible attainment. This may be an issue about the timing and level of the literacy practices required by students in learning their subjects, rather than a generic 'lack of reading'.

Although the literacy of students is a concern and learning support is available, there seems to be little explicit engagement by either staff or students in the context of subject study of the literacy practices necessary for learning. For instance, note taking can take a variety of forms, but few subject teachers address explicitly what is expected. The assumption tends to be that the generic courses provided by learning support staff are sufficient:

Interviewer: How do you feel that the students get on with taking notes ... do they know what to do ... how to take notes? Art Teacher. ... oh I would think so because ah mean they're involved in the communication unit so by then ... so they can write reports and things like that ...

Similarly, 'essays' is used as a generic term for a wide range of different types of form of assessment:

Interviewer: and do you teach report writing?

Computing Teacher: No ... no ... no ... ah mean they do

Communication class so X. would do that with them but no I

don't do report writing ...

Literacy practices tend to be part of the hidden curriculum of subject teaching, which can result in lack of alignment, e.g. lecturers using smart boards and advanced software to teach, but expecting students to make notes using pen and paper. Subject specialists tend to view the explicit teaching of literacy as the role of learning support staff, although this is not universal. Three broad views can be identified here. First, students are expected to bring the necessary literacy practices with them to their subject of study. Secondly, students are expected to develop the necessary literacy practices through emulation within the curriculum context. Thirdly, and to a lesser extent, literacy practices are to be taught 
explicitly. The precise assumptions depend upon the subject level of the course, teacher and student group.

Overall, students are expected to read a large variety of page- and screen-based texts. However, there is less variety in the forms of writing that are expected of them, in particular, more extended text during class time or for writing for assessment. Many students, in particular vocational students identified a dislike of 'writing', often associated specifically with handwriting. Extended writing is more likely to be required in core skills communication classes and academic subjects than in more vocational subject classes. The nature and purpose of the curriculum therefore influences the literacy practices expected of students. For instance:

Interviewer: do your students em ... like to write ah mean you know if you gave them the opportunity to go and write a ...? Art Teacher: No ... Interviewer: Right ...

Art Teacher: ... quite bluntly ... mine are more into doing the arty things so to be honest I don't really have the need for them to the writing ... on my ... on that side of the course ... apart from communications ...

The response in Motor Mechanics was similar:

Interviewer: They don't do a lot of writing in this course? Mechanics Teacher: No apart from the notes that I ask them to take they really don't do very much.

Interviewer: ... so they don't do a lot of writing when they go on to the NVQ other than that.

Mechanics Teacher: Other than job cards that's about all they do yeh.

This has implications for types and forms of progression by students onto further learning once they have completed their courses.

Writing was most often identified with the assessment of knowledge and competence, rather than the broader learning of the subject. Lecturing staff identified themselves as spending considerable time 'translating' assessment tasks for students. Thus, the Mechanics lecturer commented:

They're usually quite short ... they can be ambiguous ...

sometimes even during the test they will ask ... we ... we've told them that we've said look if you come across a word ... that you don't know the meaning of ... then ask.

Also, the literacy practices of assessment are not always constructively aligned with those of the subject teaching. For instance, an assessment task of writing an email asked students to write the message using pen 
and paper. This is partly due to an apparent elision of the differences between screen and page literacy practices in views of writing. Using a pen is not the same as using as keyboard, but both tend to be subsumed under the heading of 'writing'. This can be partly a resource issue of course, as funding affects the range of artefacts available for staff to draw upon in their teaching.

There are certain perceptions among some staff that the literacy practices required by the subject are higher than those required in the vocation for which students are being prepared. There also appears to be a tension around what staff would like to do and what they feel they have to do regarding assessments. Some of these issues may be the result of the ambiguous purposes of particular vocational qualifications to support progression within the subject and to enable transitions into the occupational sector. The literacy practices developed within the subject for educational progression may not be those required in the occupation and vice versa.

We see, therefore, even from our Phase 1 data, issues emerging that point to the complexity and diversity of literacy practices in further education, the ways in which teaching is based on certain expectations and resources, and the mismatches that can arise between lecturers' and students' perspectives on what is expected.

\section{Taking Issues Forward}

The above summarises the outcomes of the Phase 1 analysis of data within the LfLFE project. As we have said, this cannot be taken to be a robust set of findings, due to the random nature of the interviewees and the reliance on data of reported practice. One significant issue we have noted in our interviews of staff, for instance, is that they usually gave their perspectives of students that they teach in general. In other interviews we have conducted with staff within the project since, discussing specific students, a far more diverse range of perspectives is emerging.

However, the indications arising from this initial analysis have been used to sensitise us to particular issues in taking forward the project into Phase 2. Here, we are examining in detail the literacy practices required by the teaching of two units at different levels within 13 curriculum areas. This involves examining the texts and forms of reading and writing associated with very particular areas of learning. It also involves working with students of these units to examine the literacy practices in which they engage in their everyday lives, as well as those they manifest in college.

Here, in particular, we are interested in the nature and extent of the reading and writing students engage in outside college, the extent to which this does or does not conform to lecturers' expectations, and the 
range of reading, writing and artefacts with which students engage in learning their subject. In the process, we hope to be able to confirm or challenge some of the issues that have arisen above. The outcomes of this work will be published in later articles. Clearly being swamped with texts to read or spoon-fed that which is necessary to pass one's courses appears to be unsatisfactory to significant proportions of staff and students. This leaves the question of how this has come to be the case, and how the somewhat shared perspectives of staff and students might be drawn upon to improve the situation. Tentatively, it would appear that the perception of a 'problem' of literacy might be resulting in producing a 'problem' of literacy.

\section{Correspondence}

Richard Edwards, Centre for Research in Lifelong Learning, Institute of Education, University of Stirling, Stirling FK9 4LA, United Kingdom (r.g.edwards@stir.ac.uk).

\section{Note}

The article is based on data collected and analysed for Phase 1 of the LfLFE project. The authors would like to thank the other team members whose work has been drawn upon in writing this piece, in particular, Zoe Fowler, Roz Ivanic and Kate Miller. The research upon which the article is based is funded through the ESRC Teaching and Learning Research Programme (RES-139-25 0117).

\section{References}

Barton, D. \& Hamilton, M. (1998) Local Literacies: reading and writing in one community. London: Routledge.

Barton, D., Hamilton, M. \& Ivanic, R. (Eds) (2000) Situated Literacies: reading and writing in context. London: Routledge.

Eraut, M. (2004) Informal Learning in the Workplace, Studies in Continuing Education, 26, pp. 247-274.

Heath, S.B. (1986) Functions and Uses of Literacy, in F. De Castell, A. Luke \& K. Egan (Eds) Literacy, Society and Schooling. Cambridge: Cambridge University Press

Polkinghorne, D. (1997) Reporting Qualitative Research as Practice, in W. Tierney $\&$ Y. Lincoln (Eds) Representation and the Text: reframing the narrative voice. New York: SUNY Press.

Smith, J. (2004) Furthering Literacies: a study of literary practices in further education. Unpublished MSc, University of Stirling. 
Stronach, I \& MacLure, M. (1997) Education Research Undone: the postmodern embrace. Buckingham: Open University Press.

Tuomi-Grohn, T. \& Engestrom, Y. (Eds) (2003) Between Work and School: new perspectives on transfer and boundary-crossing. London: Pergamon. 
Richard Edwards \& June Smith 